\title{
Healthcare Worker's Mental Health and Their Associated Predictors During the Epidemic Peak of COVID-I 9
}

This article was published in the following Dove Press journal:

Psychology Research and Behavior Management

\author{
Yinmei Yang' \\ Lili Lu ${ }^{2}$ \\ Tom Chen ${ }^{3}$ \\ Shangyuan $\mathrm{Ye}$ (D) $^{3}$ \\ Mohammedhamid Osman Kelifa (ID) \\ $\mathrm{NaCao}$ \\ Qian Zhang ${ }^{4}$ \\ Tonger Liang ${ }^{5}$ \\ Wei Wang ${ }^{6}$ \\ 'School of Health Sciences, Wuhan \\ University, Wuhan, Hubei, 43007I, \\ People's Republic of China; ${ }^{2}$ Department \\ of Gastroenterology, The Affiliated \\ Hospital of Xuzhou Medical University, \\ Xuzhou, Jiangsu, 221004, People's \\ Republic of China; ${ }^{3}$ Department of \\ Population Medicine, Harvard Pilgrim \\ Health Care Institute and Harvard \\ Medical School, Boston, MA, 02I I5, USA; \\ ${ }^{4}$ Department of Dermatology, General \\ Hospital of Jincheng Coal Mining Group, \\ Jincheng, Shanxi, 048006, People's \\ Republic of China; ${ }^{5}$ Department of \\ General Practice, The Affiliated Hospital \\ of Southwest Medical University, Luzhou, \\ Sichuan, 646000, People's Republic of \\ China; ${ }^{6}$ School of Public Health, Xuzhou \\ Medical University, Xuzhou, Jiangsu, \\ 221004, People's Republic of China
}

Correspondence: Wei Wang School of Public Health, Xuzhou Medical University, Xuzhou, Jiangsu, People's Republic of China

Tel +86-I5I52II8260

Email weiwang90@I63.com

Lili Lu

Department of Gastroenterology, The Affiliated Hospital of Xuzhou Medical

University, Xuzhou, Jiangsu, 221004,

People's Republic of China

Tel +86-I5905204534

Email Iulili1990@I63.com
Introduction: The outbreak of the coronavirus disease 2019 (COVID-19) poses an unprecedented challenge to healthcare workers (HCWs) globally. This study investigated potential factors related to depression, anxiety, and stress in a sample of Chinese HCWs during the peak of the COVID-19 epidemic.

Methods: An online survey was distributed to Chinese HCWs using respondent-driven sampling. Data were collected between February 13th and February 20th, 2020, immediately following the COVID-19 contagion peak in Hubei. A total of 1208 respondents were eligible for analysis. Mental health problems and social support were measured by the Depression Anxiety Stress Scales-21 (DASS-21) and the Perceived Social Support Scale (PSS).

Results: The prevalence rates of depression, (DASS-depression > 9) anxiety (DASS-anxiety > 7) and stress (DASS-stress $>14$ ) were $37.8 \%, 43.0 \%$ and $38.5 \%$, respectively. Multivariate logistic regressions revealed that stress, anxiety, and depression were positively related to lower levels of social support, longer working hours, discrimination experience and workplace violence. The scarcity of medical equipment was correlated with increased stress and depression. Chinese HCWs working at COVID 19 designated hospitals were more likely to report anxiety. Additionally, volunteering to work in the frontline health facilities was inversely associated with depression.

Conclusion: Mental health problems among Chinese HCWs were alarming during the peak of the COVID-19 epidemic. Health facilities require appropriate and standing services that address the mental health of healthcare workers, particularly during epidemic outbreaks.

Keywords: depression, anxiety, stress, COVID-19, pandemic, healthcare workers, mental health

\section{Introduction}

At the end of the year 2019, the coronavirus disease 2019 (COVID-19) was first reported in Wuhan, China, ${ }^{1}$ and quickly proliferated nationwide. The transmissibility rate of COVID-19 was alarmingly swift and confirmed cases continued to increase in more countries. As of October 19th, 2020, the disease has resulted in a total of 39, 944,882 confirmed infections and 1,111,998 deaths globally. ${ }^{2}$ For a piece of comforting news, the National Health Commission of China (NHC) showed significant progress in curbing the epidemic, as evidenced by the overall drop in the trend of the newly confirmed cases. This could be related to a series of multifaceted public health interventions including sanitary cordon, traffic restriction, social distancing, home confinement, centralized quarantine, and universal symptom survey. ${ }^{3}$ More importantly, the mobilization of healthcare workers (HCWs) to the frontlines might have played a dominant role. 
More than 42,000 HCWs around the country were sent to Hubei province to provide medical assistance, and they cooperated with over 80,000 local HCWs to fight against COVID19. ${ }^{4}$ However, during the epidemic peak of newly confirmed cases, due to overstretched health systems and shortage of personal protective equipment, HCWs were at risk of infection as well as physical or psychological exhaustion, not to mention overwork and prolonged isolation from family. ${ }^{5-7}$ These factors can contribute to various psychological problems, such as anxiety, depression, and stress. ${ }^{8,9}$ The mental health of HCW is of great importance, as it affects their decision-making capacity, long-term wellbeing as well as the efficiency of health care delivery. ${ }^{10}$ Therefore, identifying and documenting common factors related to the mental health conditions of HCWs during the epidemic might be essential in generating insight into the development of appropriate interventions.

The mental health conditions of HCWs during the COVID19 outbreak have aroused increasing attention. For example, a review documented that a considerable proportion of HCWs experienced mental health issues during the COVID-19 pandemic and highlighted the significance of early, targeted interventions. ${ }^{11}$ During the early stage of COVID-19, Kang et $\mathrm{al}^{12}$ also reported that $34.4 \%$ of HCWs in Wuhan experienced mild mental health disturbances and emphasized the significance of personalized mental health care for frontline HCWs. Compared to nonmedical health workers, HCWs were more likely to experience insomnia, anxiety, depression, and somatization. ${ }^{13}$ However, few studies have explored the mental health status of HCWs using epidemiological data during the peak of the epidemic.

Accordingly, the present study aimed to investigate the prevalence of anxiety, depression and stress among Chinese HCWs during the peak of the COVID-19 pandemic, and identify associated factors that might put HCWs at decreased or elevated likelihoods of mental health problems.

\section{Materials and Methods}

\section{Procedure and Participants}

On February 12th, 2020, newly confirmed cases peaked at 15,152 (including a cumulative of 13,332 clinically diagnosed cases in Hubei) in China mainland. A face-to-face investigation was challenging, during this urgent circumstance. Hence, we conducted an online survey among Chinese HCWs using respondent-driven sampling. Given local differences in confirmed cases (See Figure 1), three HCWs (also known as seeds) were selected from major tertiary healthcare institutions in Hubei, Jiangsu, and Shanxi provinces. A link or a quick response $(\mathrm{QR})$ code of an online questionnaire was sent to them through WeChat, which is one of the largest social media applications in China. After completing the survey, three initial respondents were then encouraged to forward the link or QR code to others, relying on their social and professional networks. Eligible participants included doctors, nurses, and allied HCWs (pharmacists, technicians, etc.). The study period was from February 13th and February 20th, 2020, immediately following the COVID-19 contagion peak in Hubei.

We excluded incomplete or nonconforming questionnaires (answer time less than 100 seconds, the same IP address) for quality control. Finally, 1469 participants from 31 provinces in mainland China completed the questionnaire. Data for 1208 respondents were eligible for analysis, including 664 doctors (55.0\%) and 246 nurses (20.4\%).

\section{Measures \\ DASS (Depression, Anxiety, and Stress Scale)}

The Chinese-language validated Depression Anxiety Stress Scales-21 (DASS-21), ${ }^{14}$ was used to evaluate their mental health. Each subscale of depression, anxiety, and stress contains seven questions. Items were rated on a 4point Likert scale, ranging from "did not apply to me at all" (0) to "applied to me very much or most of the time" (3). The composite scores of each subscale were multiplied by 2 to make the scores comparable to the DASS$42{ }^{15,16}$ Higher scores indicate more negative emotional states in the past week. Depression, anxiety, and stress were categorized into dichotomous variables, due to nonnormal distribution. The following cut-off scores are used for each subscale: depression (DASS-depression $>$ 9), anxiety (DASS-anxiety $>7$ ), and stress (DASS-stress > 14). ${ }^{17}$ Acceptable Cronbach's alphas were observed in the current study for the depression $(0.86)$, anxiety $(0.85)$, and stress subscales $(0.85)$.

\section{PSS (Perceived Social Support Scale)}

The 12-item Perceived Social Support (PSS) scale ${ }^{18}$ was used to measure social support from families, friends, and significant others (four items per subscale). It has been validated in Chinese college students. ${ }^{19}$ Items were rated on a 7-point Likert scale ranging from "strongly disagree" (1) to "strongly agree" (7). A composite score was generated to evaluate overall social support, with higher scores denoting stronger social support. In the present study, internal consistency was excellent for the total scale $($ Cronbach's alpha $=0.94)$. 


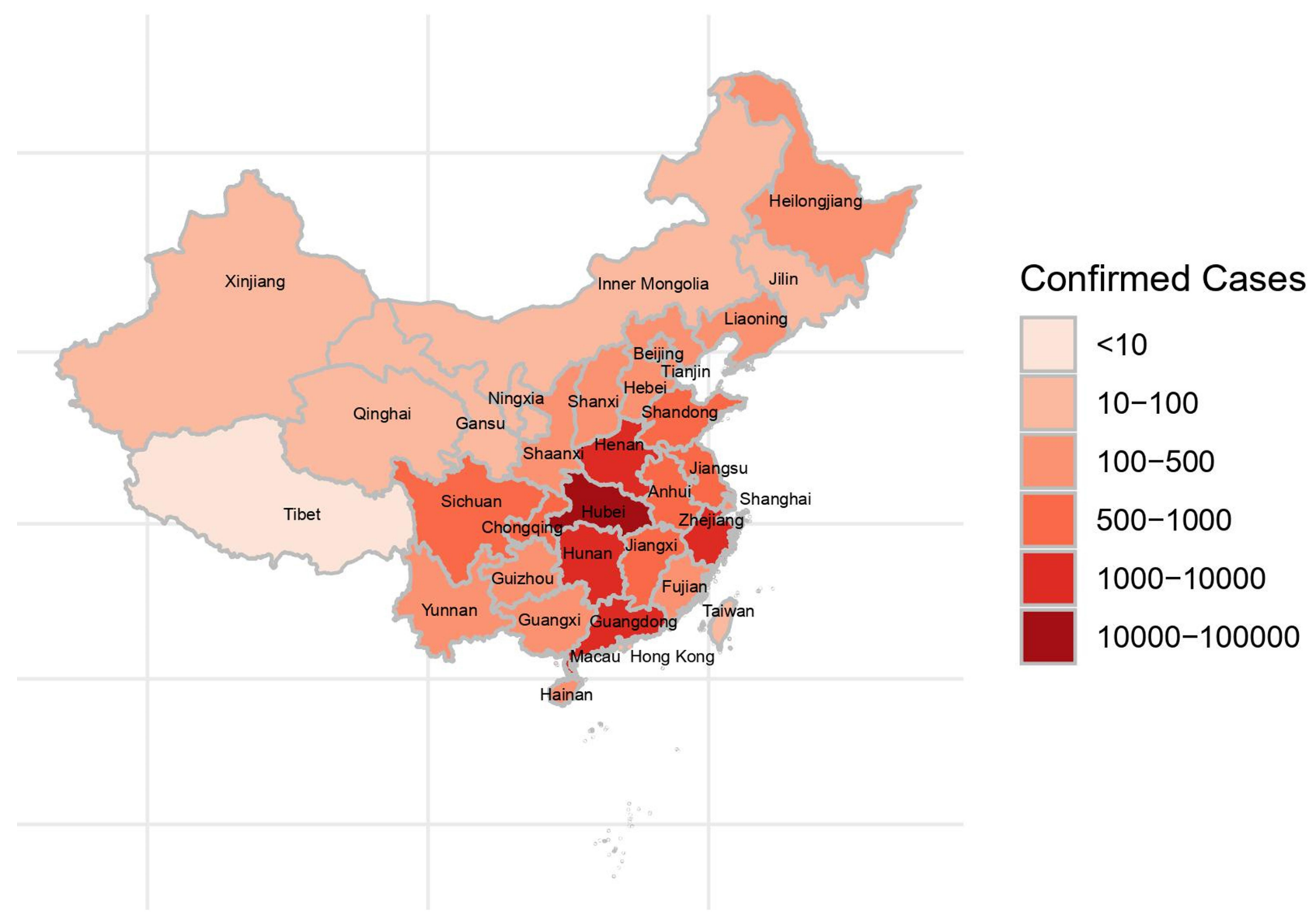

Figure I Confirmed cases by province as of February 20, 2020.

\section{Covariates}

Sociodemographic characteristics (age, gender, education, and marital status), job-related factors (job type, technical title, working time, working at a designated hospital for COVID-19, adequacy of preventive medical equipment, and volunteer status to the frontline), and interpersonal factors (discrimination experience for working in hospitals, medical workplace violence during the epidemic, patientphysician relationships compared to before the outbreak, and household transmission-related fears) were also collected.

\section{Statistical Analysis}

Age and social support were treated as continuous variables (variables were close to normal distribution), while other variables were categorical variables. The categorical variables are expressed as percentages, and continuous variables are summarized as means and standard deviations. We also conducted between-group comparisons using chi-square or $t$-tests for categorical or continuous variables. All factors with significance at the 0.05 level in univariate analyses were included in the regression model.
A series of logistic regression analyses were applied to examine potential predictors of depression, anxiety, and stress symptoms. Finally, we also conducted multiple linear regression models as robustness checks. All analyses were performed using $\mathrm{R}$ version 3.6.1.

\section{Ethical Considerations}

This project was conducted in line with the principles of the Helsinki Declaration. Ethical approval for this study was obtained from the Medical Ethics Committee of Xuzhou Medical University. Informed consent was obtained from all participants.

\section{Results}

Table 1 summarizes the characteristics of study population. There were $13.2 \%$ (159/1208), 32.8\% (396/1208), and $8.9 \%(107 / 1208)$ of respondents from Hubei, Jiangsu, and Shanxi provinces, respectively. Overall, the mean age was $33.7 \pm 7.3$ years (range $20-58$ ). The majority of respondents were females $(66.6 \%)$, highly educated (93.7\% bachelor or above), and married (72.1\%). 


\begin{tabular}{|c|c|c|c|c|c|c|c|c|c|c|}
\hline & $\begin{array}{l}\overline{8} \\
\text { Q } \\
\mathrm{v}\end{array}$ & $\underset{\substack{\alpha \\
\tilde{\sigma}}}{0}$ & & চ্口 & $\begin{array}{l}\overline{\mathrm{o}} \\
\dot{0} \\
\mathrm{v}\end{array}$ & $\begin{array}{l}\stackrel{\text { ڤn}}{0} \\
\stackrel{0}{0}\end{array}$ & $\begin{array}{l}\bar{\delta} \\
\dot{0} \\
\mathrm{v}\end{array}$ & $\begin{array}{l}\overline{\mathrm{o}} \\
\dot{0} \\
\mathrm{v}\end{array}$ & $\begin{array}{l}\overline{\mathrm{o}} \\
\dot{\mathrm{v}}\end{array}$ & $\begin{array}{l}\overline{\mathrm{o}} \\
\dot{\mathrm{d}} \\
\mathrm{v}\end{array}$ \\
\hline & $\begin{array}{l}\underset{+}{4} \\
\underline{\infty}\end{array}$ & $\begin{array}{l}\text { ఫิ } \\
\text { o. }\end{array}$ & & 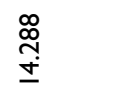 & $\begin{array}{l}\overline{\tilde{n}} \\
\stackrel{\sim}{y}\end{array}$ & 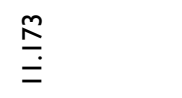 & $\begin{array}{l}\stackrel{+}{+} \\
\stackrel{\infty}{\infty}\end{array}$ & 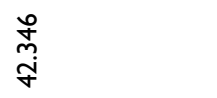 & 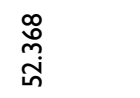 & 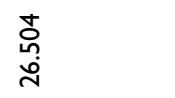 \\
\hline & 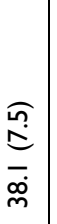 & $\begin{array}{l}\stackrel{o}{\dot{S}} \\
\stackrel{\Xi}{0} \\
\stackrel{0}{0}\end{array}$ & 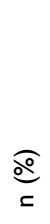 & 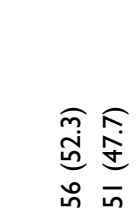 & 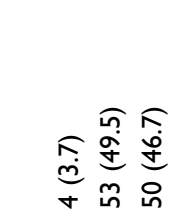 & 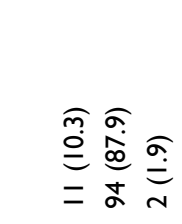 & 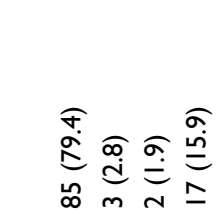 & 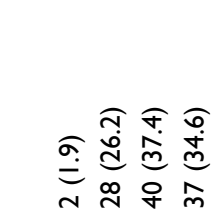 & 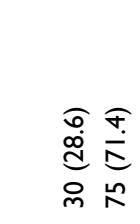 & 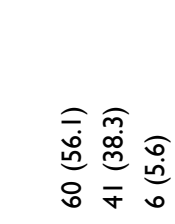 \\
\hline & $\begin{array}{l}\widehat{\bar{s}} \\
m \\
\dot{m}\end{array}$ & 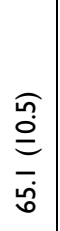 & $\underset{c}{\stackrel{\bigodot}{e}}$ & 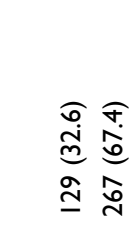 & 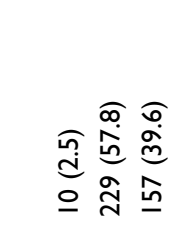 & 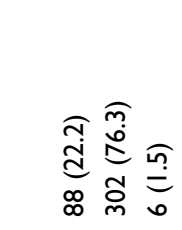 & 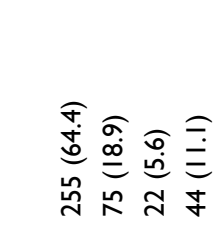 & 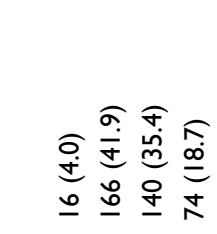 & 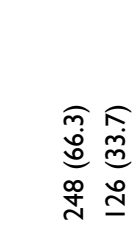 & 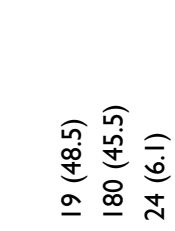 \\
\hline & $\begin{array}{l}\widehat{\infty} \\
\stackrel{\infty}{\infty} \\
\infty \\
\dot{m} \\
\tilde{m}\end{array}$ & 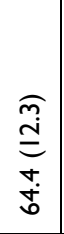 & 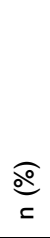 & 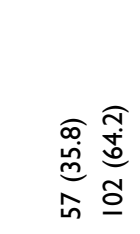 & 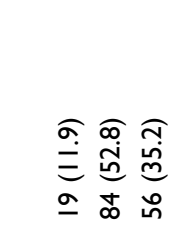 & 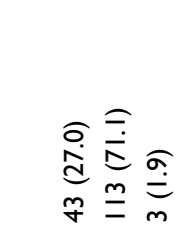 & 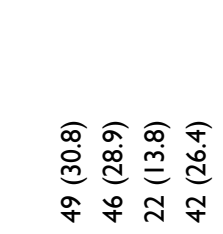 & 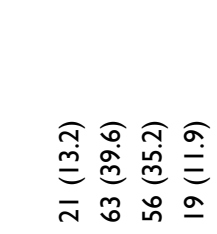 & 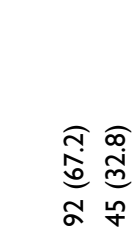 & 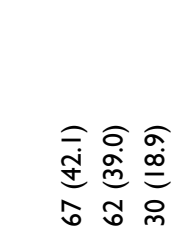 \\
\hline & $\begin{array}{l}\widehat{r} \\
\stackrel{n}{\vdots} \\
\stackrel{m}{m}\end{array}$ & $\frac{\stackrel{F}{E}}{\frac{E}{6}}$ & $\underset{c}{\stackrel{\bigodot}{9}}$ & 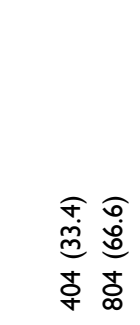 & 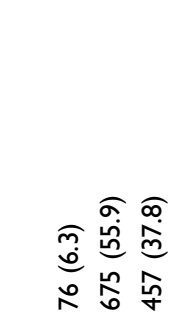 & 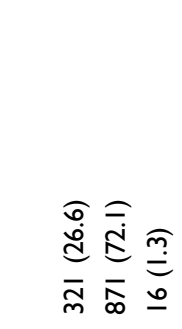 & 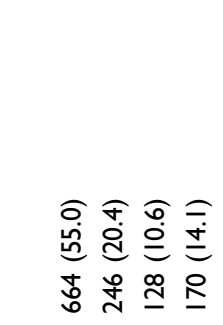 & 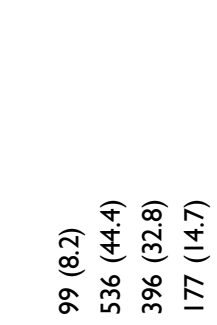 & 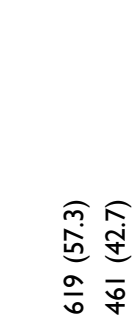 & 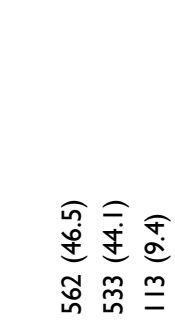 \\
\hline & 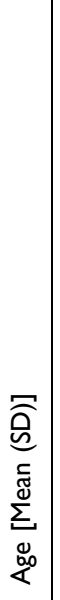 & 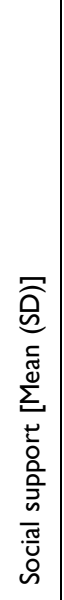 & 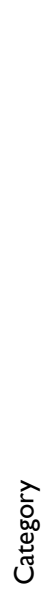 & 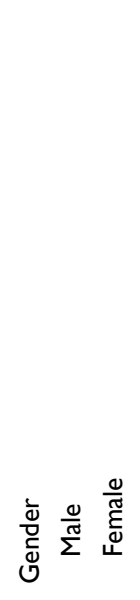 & 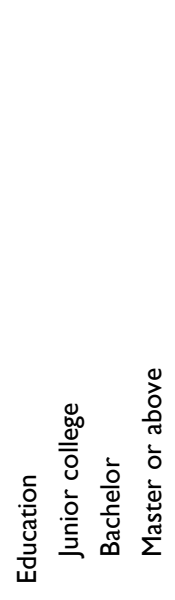 & 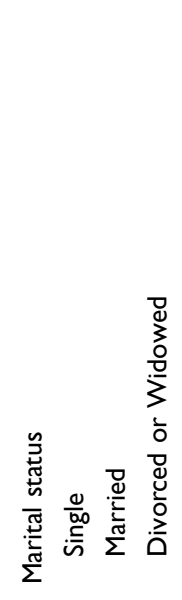 & 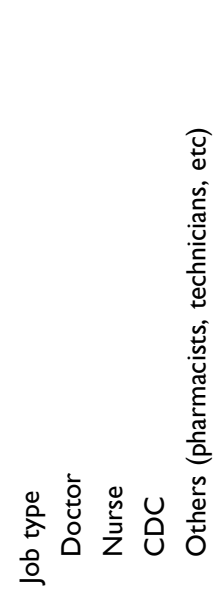 & 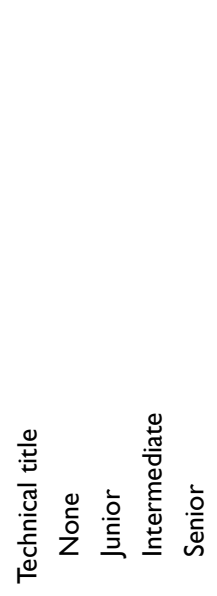 & 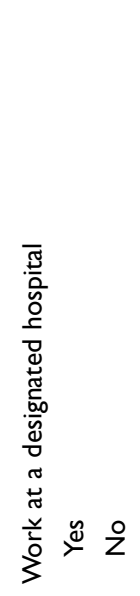 & 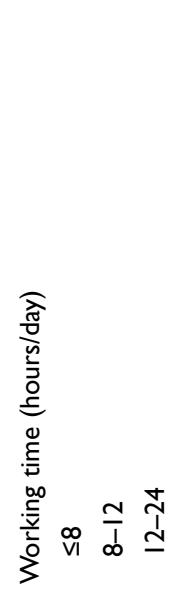 \\
\hline
\end{tabular}




\begin{tabular}{|c|c|c|c|c|c|c|c|c|}
\hline סेo & $\begin{array}{l}\text { 员 } \\
\text { on }\end{array}$ & 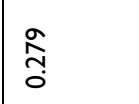 & $\begin{array}{l}\bar{o} \\
\dot{v}\end{array}$ & $\bar{o}$ & 志 & 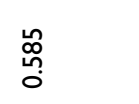 & 菅 & $\frac{ \pm}{0}$ \\
\hline 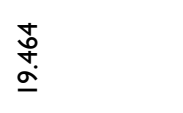 & $\stackrel{\circ}{\stackrel{\circ}{=}}$ & 岕 & 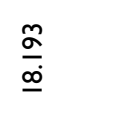 & $\begin{array}{l}\stackrel{\alpha}{\alpha} \\
\stackrel{\alpha}{\alpha}\end{array}$ & $\stackrel{\circ}{\stackrel{2}{\Sigma}}$ & $\underset{\sigma o}{\sigma}$ & $\begin{array}{l}\stackrel{\circ}{\circ} \\
\stackrel{\circ}{\circ}\end{array}$ & $\underset{\substack{\infty \\
m}}{ }$ \\
\hline 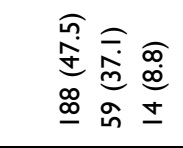 & 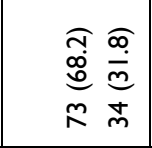 & 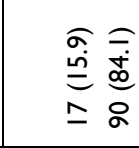 & 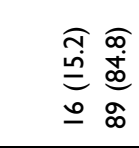 & 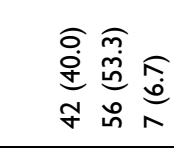 & 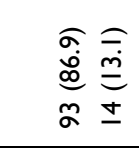 & 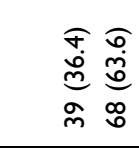 & 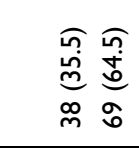 & 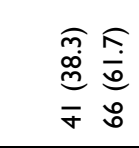 \\
\hline 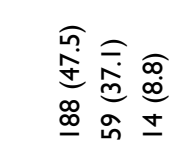 & 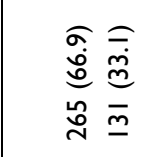 & 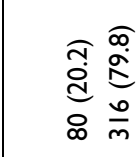 & 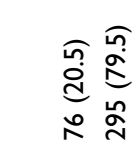 & 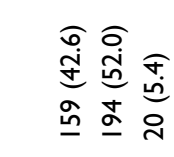 & 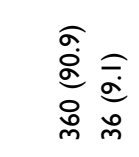 & 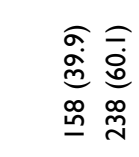 & 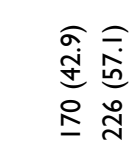 & 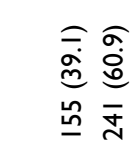 \\
\hline 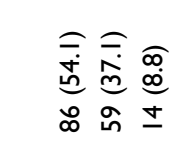 & 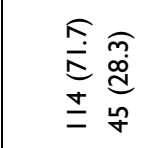 & 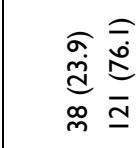 & 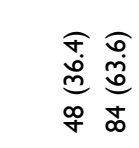 & 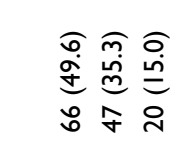 & 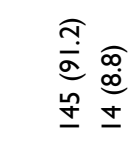 & 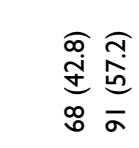 & 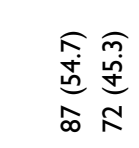 & 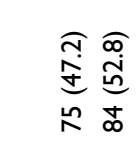 \\
\hline 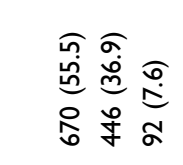 & 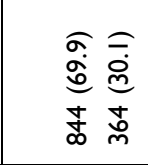 & 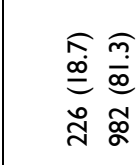 & 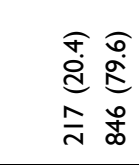 & 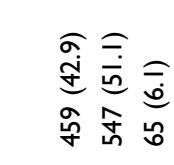 & 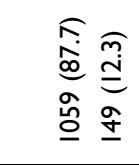 & 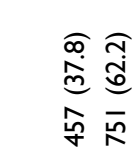 & 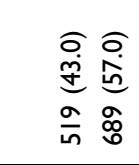 & 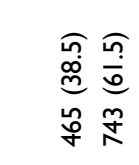 \\
\hline 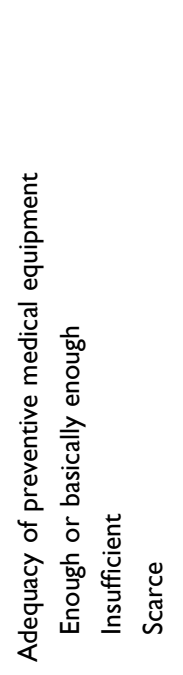 & 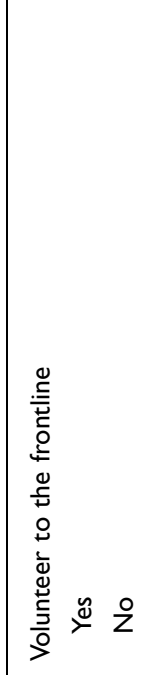 & 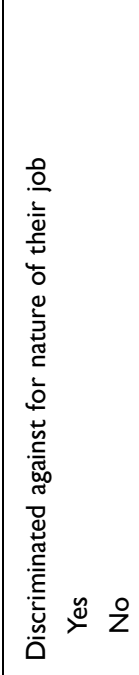 & 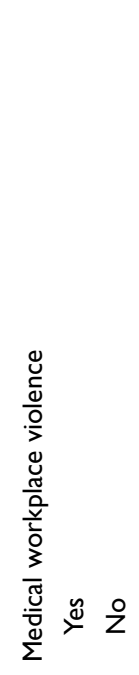 & 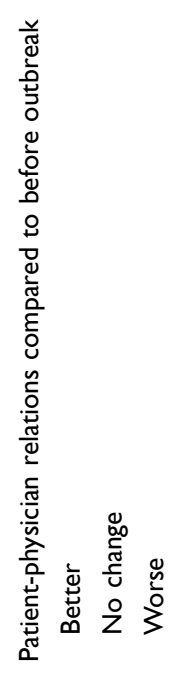 & 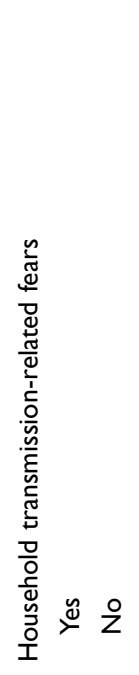 & 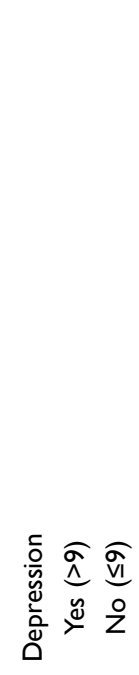 & 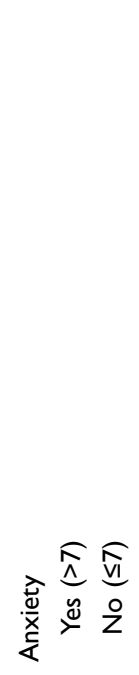 & 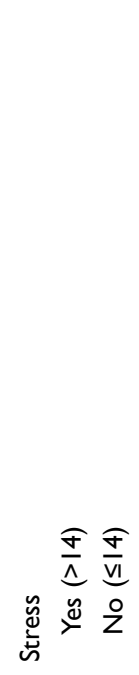 \\
\hline
\end{tabular}


Table 2 Correlations Between Study Variables

\begin{tabular}{|l|l|l|l|l|l|}
\hline & Mean (SD) & Stress & Anxiety & Depression & Social Support \\
\hline Stress & II.7 (8.3) & I & & & \\
Anxiety & $7.9(7.6)$ & $0.777 * * *$ & 1 & & \\
Depression & $8.6(7.7)$ & $0.768 * * *$ & $0.719 * * *$ & 1 & \\
Social support & $66.1(11.7)$ & $-0.270 * * *$ & $-0.260 * * *$ & $-0.346 * * *$ & 1 \\
\hline
\end{tabular}

Note: $* * * p<0.001$.

Abbreviation: SD, standard deviation.

Furthermore, most of the respondents had a technical title of junior or above (91.8\%), worked at a designated hospital $(57.3 \%)$, worked more than eight hours per day (53.5\%), and volunteered to be on the frontline (69.9\%). Logistically, $45.5 \% \mathrm{HCWs}$ were facing insufficient or scarce preventive medical equipment. Interpersonally, $18.7 \%$ of HCWs were discriminated for working in hospitals during the COVID-19 outbreak, over one fifth suffered from medical conflicts during the epidemic, most (87.7\%) had fears regarding transmitting COVID-19 to household members, and $6.1 \%$ reported worsening patient-physician relations. Prevalence rates of $37.8 \%, 43.0 \%$, and $38.5 \%$ were reported for depression, anxiety, and stress symptoms, respectively. HCWs in Hubei province had higher prevalence rates of depression, anxiety, and stress than those from Jiangsu and Shanxi, but there was significant difference only in anxiety.

The means and standard deviations for social support, depression, anxiety, and stress scales are listed in Table 2. The mean scores of depression, anxiety, and stress symptoms were 8.6, 7.9, and 11.7, respectively. All correlation coefficients were statistically significant at the 0.001 level.

Univariate analyses of these three outcome variables (stress, anxiety and depression) are summarized in Table 3.

After controlling for covariates, social support, longer working hours, discrimination experience, medical workplace violence, and adequacy of preventive medical equipment significantly predicted stress. Anxiety was associated with social support, working at designated hospitals, longer working hours, discrimination experience, and medical workplace violence. HCWs reporting depression were more likely to work longer hours, experience discrimination, report inadequacy of preventive medical equipment, and experience medical workplace violence, but less likely to have high scores of social support and volunteer to the frontline (See Table 4). Our results were robust by multiple linear regression models (see Appendix A).

\section{Discussion}

We evaluated the prevalence and associated factors of mental health among Chinese HCWs during the peak of the COVID19 epidemic. Our results showed that the mean scores of depression, anxiety, and stress symptoms were 8.6, 7.9, and 11.7, respectively. This is in line with a study conducted a year after the SARS outbreak among HCWs in SARS isolation units. ${ }^{20}$ When denoted by categorical variables, symptoms of depression, anxiety, and stress were observed in $37.8 \%, 43.0 \%$, and $38.5 \%$ of Chinese HCWs, higher than Chinese general public during the initial stage of the COVID-19 outbreak $(16.5 \%, 28.8 \%$, and $8.1 \%$ reported depression, anxiety, and stress, respectively) ${ }^{21}$ and Italian general population. ${ }^{22}$ Similarly, research from China, Italy, Turkey, Spain and Iran reported higher pooled prevalence among healthcare workers than the general population. ${ }^{23}$ Additionally, HCWs from Hubei province reported more severe mental health problems than those from Jiangsu and Shanxi. Given the sharp increase of confirmed cases during our study period, HCWs are extremely short-staffed in Hubei province, where COVID-19 was first identified and the majority of patients and deaths came from. HCWs were under insurmountable psychological pressure, further increasing their vulnerability to mental health problems, endangering the functioning of the entire health care system.

Moreover, our findings demonstrated that social support appeared to exert a protective effect on psychological morbidity among HCWs. During the outbreak of serious infectious diseases, HCWs are worried about being infected and are under tremendous pressure, but social support can alleviate their mental health problems. ${ }^{24}$ Similarly, some scholars have noted that social support was negatively related to anxiety and stress among HCWs who treated patients with COVID-19, ${ }^{25}$ and perceived social support was negatively correlated to DASS scores. ${ }^{26}$ Kawachi and Berkman ${ }^{27}$ also argued that social support might benefit mental health by producing positive psychological states, including a sense of purpose, belongingness, and security, as well as recognition of self-worth. 


\begin{tabular}{|c|c|c|c|c|c|c|c|c|c|c|}
\hline$a$ & & 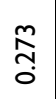 & $\begin{array}{l}\overline{\mathrm{o}} \\
\dot{\mathrm{d}}\end{array}$ & $\stackrel{\infty}{\circ}$ & 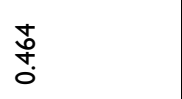 & $\stackrel{\substack{m \\
0}}{0}$ & ث̊. & $\frac{\stackrel{\infty}{\infty}}{0}$ & 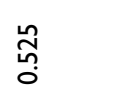 & $\begin{array}{l}\overline{\mathrm{o}} \\
\mathrm{i} \\
\mathrm{v}\end{array}$ \\
\hline & $\stackrel{\varrho}{\check{\nu}}$ & $\begin{array}{l}\widehat{\bar{D}} \\
\overline{0} \\
\tilde{m}\end{array}$ & $\begin{array}{l}\stackrel{\substack{n\\
}}{m} \\
\stackrel{m}{0}\end{array}$ & 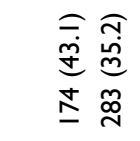 & 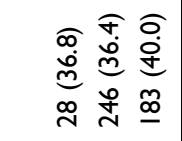 & 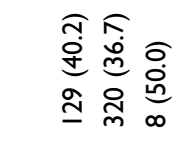 & 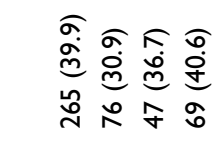 & 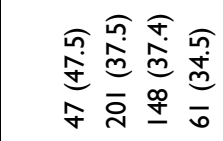 & 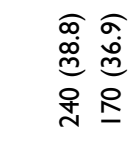 & 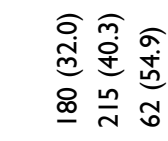 \\
\hline 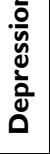 & $\stackrel{\circ}{\mathbf{z}}$ & $\begin{array}{l}\widehat{m} \\
\stackrel{\vdots}{\vdots} \\
\sigma \\
\dot{m}\end{array}$ & 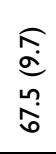 & 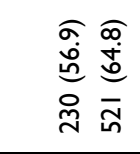 & 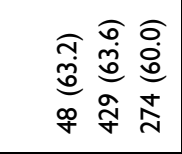 & 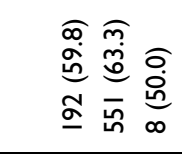 & 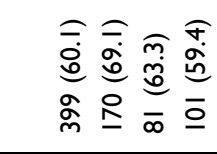 & 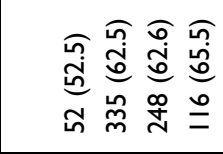 & 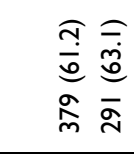 & 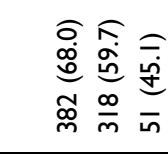 \\
\hline$a$ & & $\stackrel{\infty}{\circ}$ & $\begin{array}{l}\bar{\alpha} \\
\text { ì }\end{array}$ & $\begin{array}{l}\text { ô } \\
\text { ô }\end{array}$ & $\stackrel{\substack{n \\
\hat{0}}}{0}$ & $\begin{array}{l}\text { ర్ } \\
\text { Oे }\end{array}$ & \begin{tabular}{l} 
ֻू \\
\hdashline \\
\hdashline
\end{tabular} & $\begin{array}{l}\infty \\
\stackrel{\infty}{\circ} \\
0\end{array}$ & $\frac{1}{0}$ & $\begin{array}{l}\bar{o} \\
\text { ì }\end{array}$ \\
\hline & 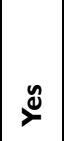 & $\begin{array}{l}\stackrel{a}{c} \\
\frac{\dot{m}}{m}\end{array}$ & 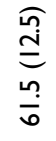 & 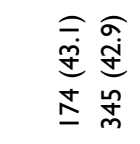 & 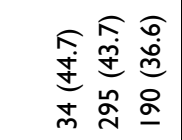 & 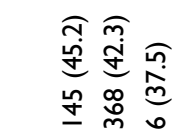 & 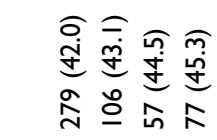 & 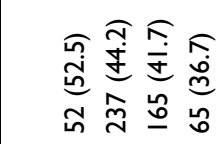 & 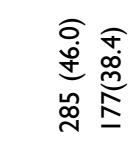 & 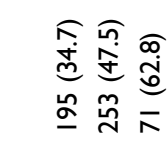 \\
\hline $\begin{array}{l}\vec{a} \\
\frac{0}{x} \\
\frac{x}{4} \\
\end{array}$ & ż & 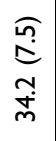 & & 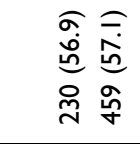 & 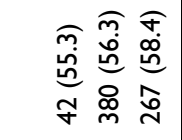 & 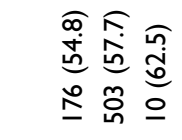 & 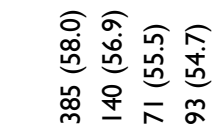 & 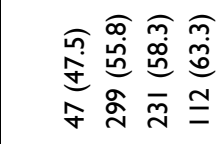 & 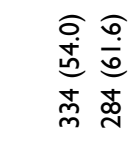 & 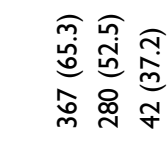 \\
\hline$a$ & & 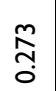 & 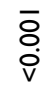 & $\stackrel{n}{\circ}$ & 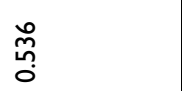 & $\begin{array}{l}\hat{a} \\
\alpha \\
o\end{array}$ & $\frac{\pi}{0}$ & $\frac{\pi}{0}$ & 。̊ & $\begin{array}{l}\bar{Q} \\
\dot{0} \\
\mathrm{v}\end{array}$ \\
\hline & $\stackrel{\varrho}{\nu}$ & 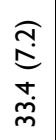 & 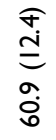 & 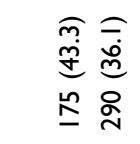 & 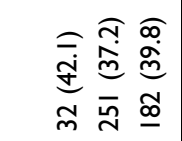 & 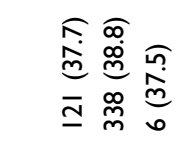 & 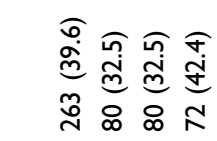 & 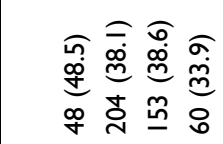 & 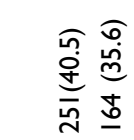 & 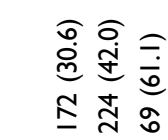 \\
\hline 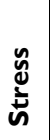 & $\stackrel{\circ}{\mathbf{z}}$ & 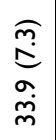 & 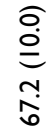 & 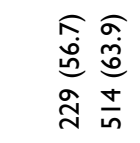 & 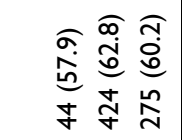 & 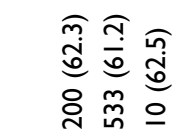 & 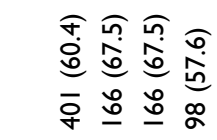 & 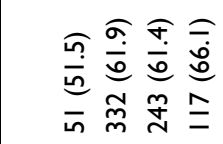 & 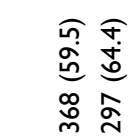 & 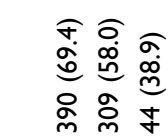 \\
\hline$\frac{\frac{y}{0}}{\frac{0}{\frac{\sigma}{2}}}$ & & $\stackrel{8}{⿺}$ & 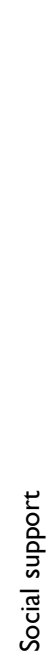 & 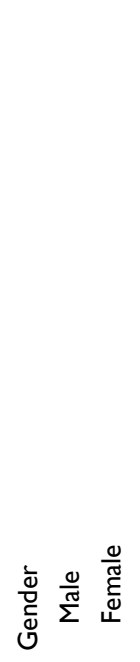 & 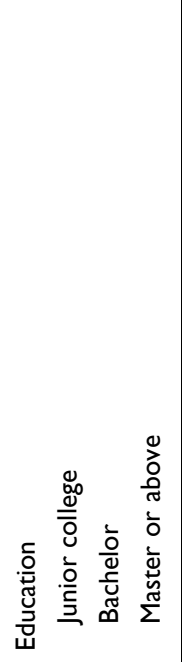 & 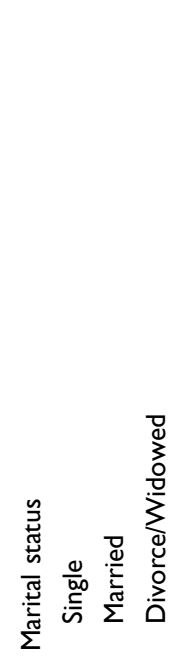 & 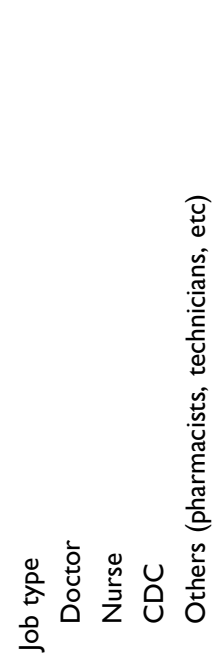 & 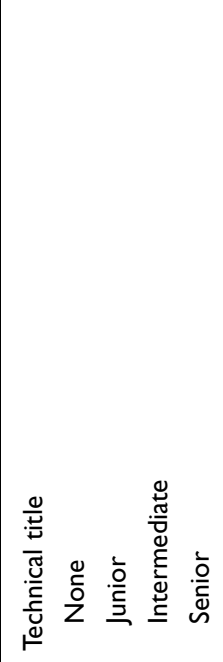 & 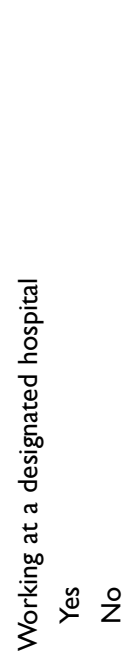 & 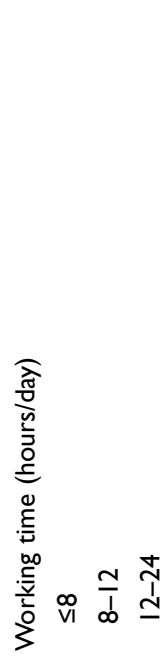 \\
\hline
\end{tabular}




\begin{tabular}{|c|c|c|c|c|c|c|c|}
\hline \multicolumn{2}{|l|}{ a } & $\begin{array}{l}\bar{\partial} \\
\dot{0} \\
\mathrm{v}\end{array}$ & o̊ & $\begin{array}{l}\bar{\partial} \\
\dot{0}\end{array}$ & $\begin{array}{l}\bar{\delta} \\
\dot{0} \\
\dot{v}\end{array}$ & ঃ̊ & ס̄ \\
\hline \multirow[b]{2}{*}{ 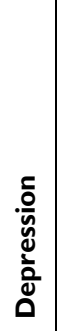 } & $\stackrel{\nu}{\nu}$ & 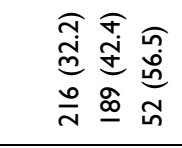 & 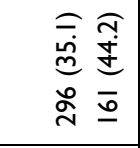 & 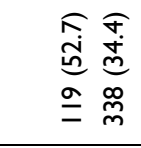 & 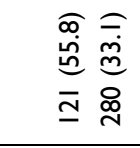 & 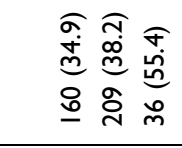 & 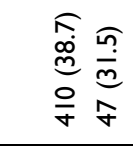 \\
\hline & z & 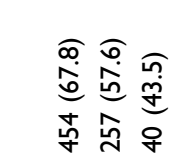 & 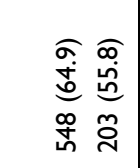 & 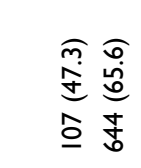 & 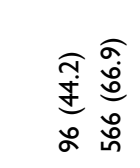 & 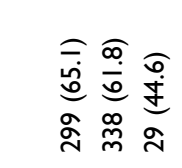 & \begin{tabular}{ll}
$\widehat{m}$ & \multicolumn{1}{c}{} \\
$\overline{0}$ & 0 \\
0 & 0 \\
0 & 0 \\
0 & 0
\end{tabular} \\
\hline \multicolumn{2}{|l|}{ e } & $\bar{o}$ & $\begin{array}{l}\text { \&े } \\
\stackrel{0}{0} \\
0\end{array}$ & $\begin{array}{l}\overline{\mathrm{o}} \\
\dot{\mathrm{v}}\end{array}$ & $\begin{array}{l}\bar{\delta} \\
\dot{0} \\
\dot{v}\end{array}$ & $\frac{\mathrm{T}}{0}$ & o̊ \\
\hline \multirow[b]{2}{*}{ 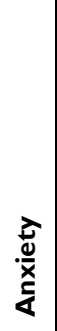 } & 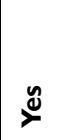 & 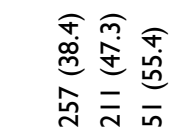 & 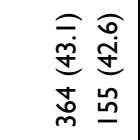 & 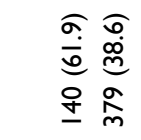 & 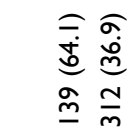 & 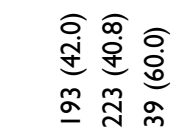 & 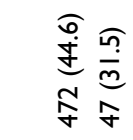 \\
\hline & Ż & 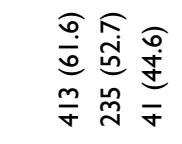 & 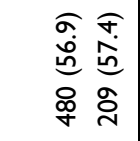 & 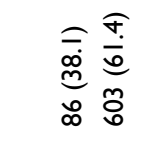 & 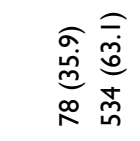 & 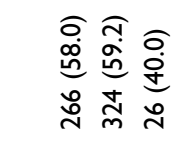 & 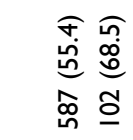 \\
\hline \multicolumn{2}{|l|}{ a } & $\begin{array}{l}\bar{\delta} \\
\overline{0} \\
\mathrm{v}\end{array}$ & $\frac{o}{m}$ & $\begin{array}{l}\overline{8} \\
\bar{v} \\
\mathrm{v}\end{array}$ & $\begin{array}{l}\overline{\mathrm{o}} \\
\dot{\mathrm{v}}\end{array}$ & $\underset{\tilde{\delta}}{\tilde{O}}$ & ঃ̊ \\
\hline \multirow[b]{2}{*}{ 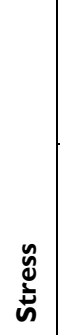 } & $\stackrel{\nu}{\nu}$ & 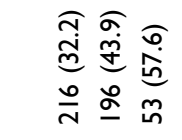 & 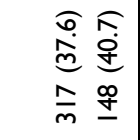 & 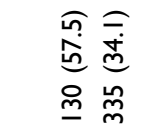 & 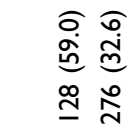 & 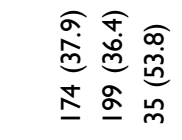 & 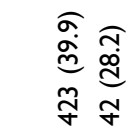 \\
\hline & z & 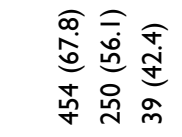 & 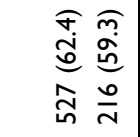 & 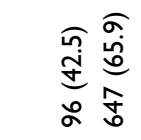 & 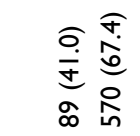 & 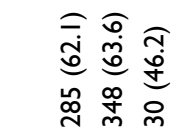 & 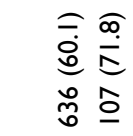 \\
\hline \multicolumn{2}{|l|}{ 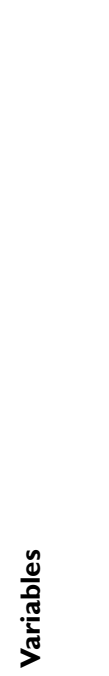 } & 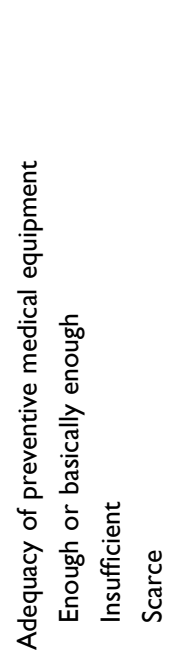 & 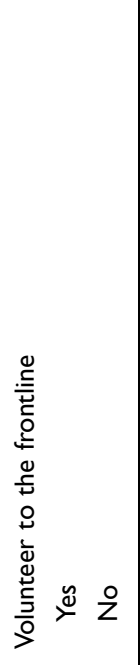 & 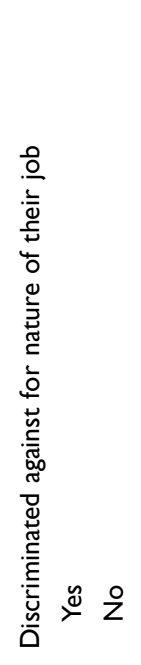 & 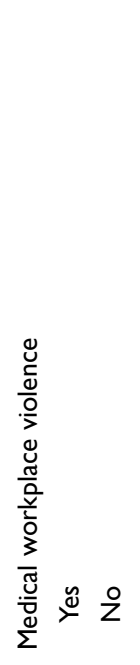 & 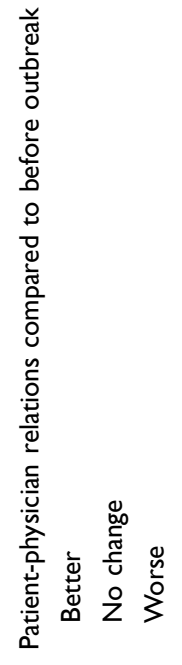 & 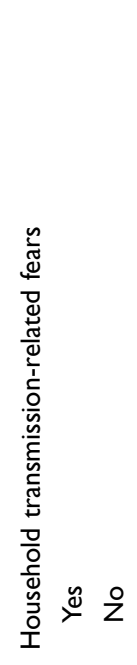 \\
\hline
\end{tabular}




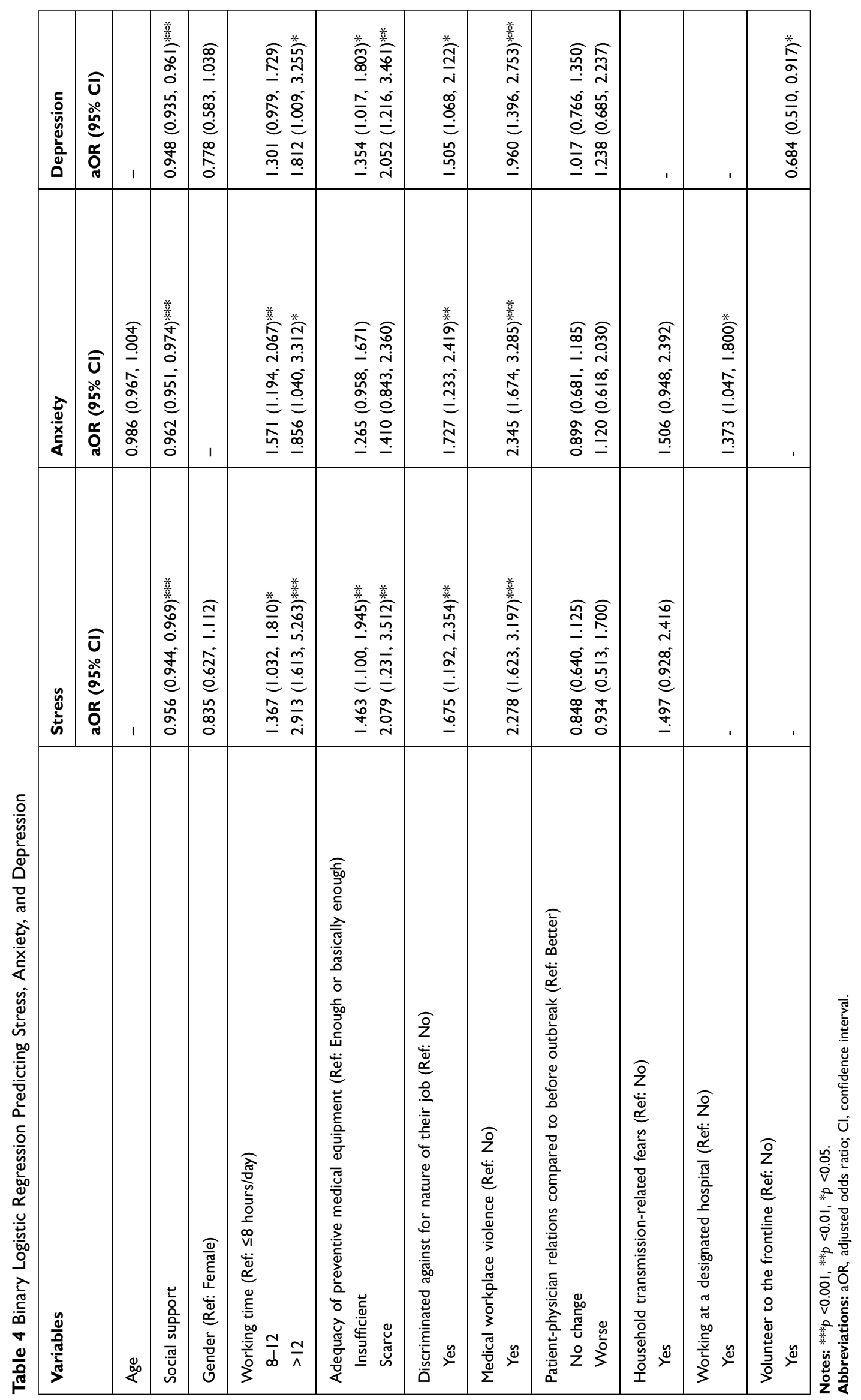


Thus, how social support mitigates the long-term impacts of the COVID-19 pandemic on HCW's mental health warrants further research.

Multiple factors related to the clinical environment may contribute to psychological distress, including longer working hours, scarcity of medical equipment, working at designated hospitals, and the experience of medical workplace violence. As the tide of patients rises, HCWs are obliged to overwork to meet health requirements, which may result in mental and physical exhaustion. Equally worrisome is a shortage of medical equipment, putting HCWs at elevated risk of being infected. ${ }^{28,29}$ Based on experiences from the SARS outbreak in Hong Kong, perceived inadequacy of protective facilities significantly predicted psychological morbidity among frontline HCWs. ${ }^{30}$ Also, HCWs working at designated hospitals suffer from a high risk of pathogen exposure, due to close contacts with confirmed or suspected cases. Meanwhile, a surge of demand on the health care system further exacerbates the relationship between doctors and patients. Our previous study also revealed that workplace violence exerted detrimental effects on mental health among Chinese HCWs using propensity score matching analysis. ${ }^{31}$ Similarly, a cross-sectional study among nurses in Hong Kong revealed that workplace violence against clinicians was significantly related to anxiety. ${ }^{32}$ Consequently, the perception of an unsafe clinical environment plays a crucial role in developing great psychological pressure. Therefore, future research should focus on providing safe environments for HCWs.

Furthermore, HCWs who volunteered to the frontline were less likely to report depression, as they might be psychologically prepared or have richer experience meeting the challenge. ${ }^{30}$ In addition, stigmatizing HCWs because they worked in hospitals during the epidemic poses a detrimental effect on their mental health. Previous research conducted in a large tertiary care institution during the peak of the SARS outbreak similarly demonstrated that discrimination negatively affected the health of HCWs. ${ }^{33}$

Several limitations should be acknowledged in the current study. First, this online survey using non-probability sampling might not be representative of Chinese HCWs, as those affected most by the outbreak might be missed by the study. Further, as this study was distributed through WeChat, the generalizability of our findings may be limited. Second, causal relationships cannot be elucidated from this cross-sectional study. Third, the selfreporting nature of questionnaires may invoke under- or over-report of mental health symptoms. Forth, despite we recruited participants from 31 provinces, it was not suitable to conduct multilevel models in the current study, due to the small sample size in several provinces. Finally, data collection was conducted in China, future studies should include a more diverse sample.

\section{Conclusions}

The current study showed that a large portion of Chinese HCWs experienced mental health problems during the peak of the COVID 19 epidemic. While providing social support seems to be an understandable choice in alleviating workers' psychological pressure, ensuring a safe working environment through logistical support, nondiscrimination, and arrangement of adequate rest, as well as reductions of medical workplace violence appear to be just as important. Consulting services and psychological interventions should be vigilant to identify early signs of mental health problems.

\section{Acknowledgments}

We would like to thank all participations in the current study.

\section{Funding}

The study was supported by the Postdoctoral research fund of Jiangsu province [grant number 2020Z177], the China Association for Science and Technology [20200608CG080611], Universities' philosophy and social science researches in Jiangsu Province [2020SJA1053] and by the National Natural Science Foundation of China [82003484].

\section{Disclosure}

The authors declare no conflicts of interest.

\section{References}

1. Li Q, Guan X, Wu P, et al. Early transmission dynamics in Wuhan, China, of novel coronavirus-infected pneumonia. $N$ Engl $J$ Med. 2020;382(13):1199-1207. doi:10.1056/NEJMoa2001316

2. WHO. Coronavirus disease (COVID-19) pandemic. Available from: https://www.who.int/emergencies/diseases/novel-coronavirus-2019. Accessed October 19, 2020.

3. Pan A, Liu L, Wang C, et al. Association of public health interventions with the epidemiology of the COVID-19 outbreak in Wuhan, China. JAMA. 2020;323(19):1915-1923. doi:10.1001/jama.2020.6130

4. Healthcare worker waves goodbye to Wuhan. Available from: http:// www.china.org.cn/china/2020-04/14/content_75928730.htm. Accessed October 19, 2020.

5. Kang L, Li Y, Hu S, et al. The mental health of medical workers in Wuhan, China dealing with the 2019 novel coronavirus. Lancet Psychiatry. 2020;7(3):e14. doi:10.1016/S2215-0366(20)30047-X

6. Ong JJY, Bharatendu C, Goh Y, et al. Headaches associated with personal protective equipment - a cross-sectional study among frontline healthcare workers during COVID-19. Headache. 2020;60 (5):864-877. doi:10.1111/head.13811

7. Dong ZQ, Ma J, Hao YN, et al. The social psychological impact of the COVID-19 pandemic on medical staff in China: a cross-sectional study. Eur Psychiatry. 2020;63(1):e65. doi:10.1192/j.eurpsy.2020.59 
8. Song X, Fu W, Liu X, et al. Mental health status of medical staff in emergency departments during the coronavirus disease 2019 epidemic in China. Brain Behav Immun. 2020;88:60-65. doi:10.1016/j. bbi.2020.06.002

9. Chen J, Liu X, Wang D, et al. Risk factors for depression and anxiety in healthcare workers deployed during the COVID-19 outbreak in China. Soc Psychiatry Psychiatr Epidemiol. 2020;1-9. doi:10.1007/ s00127-020-01954-1

10. Xiang YT, Yang Y, Li W, et al. Timely mental health care for the 2019 novel coronavirus outbreak is urgently needed. Lancet Psychiatry. 2020;7(3):228-229. doi:10.1016/S2215-0366(20)30046-8

11. Pappa S, Ntella V, Giannakas T, Giannakoulis VG, Papoutsi E, Katsaounou P. Prevalence of depression, anxiety, and insomnia among healthcare workers during the COVID-19 pandemic: a systematic review and meta-analysis. Brain Behav Immun. 2020;88:901907. doi:10.1016/j.bbi.2020.05.026

12. Kang L, Ma S, Chen M, et al. Impact on mental health and perceptions of psychological care among medical and nursing staff in Wuhan during the 2019 novel coronavirus disease outbreak: a cross-sectional study. Brain Behav Immun. 2020;87:11-17. doi:10.1016/j.bbi.2020.03.028

13. Zhang WR, Wang K, Yin L, et al. Mental health and psychosocial problems of medical health workers during the COVID-19 epidemic in China. Psychother Psychosom. 2020;89(4):242-250. doi:10.1159/ 000507639

14. Taouk M, Lovibond P, Laube R. Psychometric Properties of a Chinese Version of the 21-Item Depression Anxiety Stress Scales (DASS21). Sydney: Cumberland Hospital; 2001.

15. Sinclair SJ, Siefert CJ, Slavin-Mulford JM, Stein MB, Renna M, Blais MA. Psychometric evaluation and normative data for the depression, anxiety, and stress scales-21 (DASS-21) in a nonclinical sample of U.S. adults. Eval Health Prof. 2012;35(3):259-279. doi:10.1177/0163278711424282

16. Yohannes AM, Dryden S, Hanania NA. Validity and responsiveness of the Depression Anxiety Stress Scales-21 (DASS-21) in COPD. Chest. 2019;155(6):1166-1177. doi:10.1016/j.chest.2018.12.010

17. Lovibond S, Lovibond P. Manual for the Depression Anxiety Stress Scales. 2nd ed. Sydney, Australia: Psychology Foundation; 1995.

18. Zimet GD, Dahlem NW, Zimet SG, Farley GK. The multidimensional scale of perceived social support. J Pers Assess. 1988;52 (1):30-41. doi:10.1207/s15327752jpa5201_2

19. Zhang M, Zhang J, Zhang F, Zhang L, Feng D. Prevalence of psychological distress and the effects of resilience and perceived social support among Chinese college students: does gender make a difference? Psychiatry Res. 2018;267:409-413. doi:10.1016/j. psychres.2018.06.038

20. McAlonan GM, Lee AM, Cheung V, et al. Immediate and sustained psychological impact of an emerging infectious disease outbreak on health care workers. Can J Psychiatry. 2007;52(4):241-247. doi:10.1177/070674370705200406
21. Wang C, Pan R, Wan X, et al. A longitudinal study on the mental health of general population during the COVID-19 epidemic in China. Brain Behav Immun. 2020;87:40-48. doi:10.1016/j. bbi.2020.04.028

22. Moccia L, Janiri D, Pepe M, et al. Affective temperament, attachment style, and the psychological impact of the COVID-19 outbreak: an early report on the Italian general population. Brain Behav Immun. 2020;87:75-79. doi:10.1016/j.bbi.2020.04.048

23. Luo M, Guo L, Yu M, Jiang W, Wang H. The psychological and mental impact of coronavirus disease 2019 (COVID-19) on medical staff and general public: a systematic review and meta-analysis.

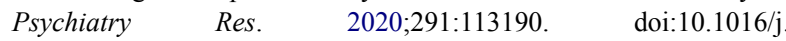
psychres.2020.113190

24. Lu YC, Shu BC, Chang YY, Lung FW. The mental health of hospital workers dealing with severe acute respiratory syndrome. Psychother Psychosom. 2006;75(6):370-375. doi:10.1159/000095443

25. Xiao H, Zhang Y, Kong D, Li S, Yang N. The effects of social support on sleep quality of medical staff treating patients with Coronavirus Disease 2019 (COVID-19) in January and February 2020 in China. Med Sci Monit. 2020;26:e923549. doi:10.12659/ MSM.923549

26. Si MY, Su XY, Jiang Y, et al. Psychological impact of COVID-19 on medical care workers in China. Infect Dis Poverty. 2020;9(1):113. doi:10.1186/s40249-020-00724-0

27. Kawachi I, Berkman LF. Social ties and mental health. J Urban Health. 2001;78(3):458-467. doi:10.1093/jurban/78.3.458

28. Ranney ML, Griffeth V, Jha AK. Critical supply shortages - the need for ventilators and personal protective equipment during the Covid19 pandemic. $N$ Engl J Med. 2020;382(18):e41. doi:10.1056/ NEJMp2006141

29. Xiang YT, Jin Y, Wang Y, Zhang Q, Zhang L, Cheung T. Tribute to health workers in China: a group of respectable population during the outbreak of the COVID-19. Int J Biol Sci. 2020;16(10):1739-1740. doi:10.7150/ijbs.45135

30. Tam CW, Pang EP, Lam LC, Chiu HF. Severe acute respiratory syndrome (SARS) in Hong Kong in 2003: stress and psychological impact among frontline healthcare workers. Psychol Med. 2004;34 (7):1197-1204. doi:10.1017/s0033291704002247

31. Wang W, Lu L, Kelifa MM, et al. Mental health problems in Chinese healthcare workers exposed to workplace violence during the COVID-19 outbreak: a cross-sectional study using propensity score matching analysis. Risk Manag Healthc Policy. 2020;13:2827-2833. doi:10.2147/RMHP.S279170

32. Cheung T, Yip PS. Workplace violence towards nurses in Hong Kong: prevalence and correlates. BMC Public Health. 2017;17 (1):196. doi:10.1186/s12889-017-4112-3

33. Nickell LA, Crighton EJ, Tracy CS, et al. Psychosocial effects of SARS on hospital staff: survey of a large tertiary care institution. CMAJ. 2004;170(5):793-798. doi:10.1503/cmaj.1031077
Psychology Research and Behavior Management

\section{Publish your work in this journal}

Psychology Research and Behavior Management is an international, peer-reviewed, open access journal focusing on the science of psychology and its application in behavior management to develop improved outcomes in the clinical, educational, sports and business arenas. Specific topics covered in the journal include: Neuroscience, memory and decision making; Behavior modification and management; Clinical applications; Business and sports performance management; Social and developmental studies; Animal studies. The manuscript management system is completely online and includes a very quick and fair peer-review system, which is all easy to use. Visit http://www. dovepress.com/testimonials.php to read real quotes from published authors. 